\title{
Parental factors in cognitive outcome of non-handicapped low birthweight infants
}

\author{
Kristian Sommerfelt, Bjørn Ellertsen, Trond Markestad
}

\begin{abstract}
A population based cohort of 144 children weighing less than $2000 \mathrm{~g}$ who were without major handicap, and a random control sample of 163 children born at term and weighing over $3000 \mathrm{~g}$ were investigated. The aim was to assess the relative importance for cognitive development at 5 years of age, of birthweight, parental demographic factors, and factors related to the environment in which the child was reared. The mean non-verbal IQ was $6 \cdot 1$ points lower $(95 \% \mathrm{CI}, 2 \cdot 3$ to 10$)$ for the low birthweight (LBW) group, but the difference was reduced to 4.8 points $(95 \% \mathrm{CI}$, $1 \cdot 1$ to $8 \cdot 5)$ after adjusting for confounding parental demographic and childrearing factors. The verbal IQ was similar for the two groups after such adjustment. Paternal education was the main confounding variable, and demographic factors such as parental education and family income were much stronger predictors of child IQ than birthweight or factors related to the childrearing environment.

There was no evidence that the cognitive development of low birthweight children was more sensitive to a nonoptimal childrearing environment than that of normal birthweight children. These findings indicate that the risk of impaired cognitive development increases with decreasing socioeconomic status, and that this risk is much larger than, and independent of, the small risk attributable to low birthweight.

(Arch Dis Child 1995; 73: F135-F142)
\end{abstract}

Keywords: low birthweight infant, socioeconomic status, pre-school, cognitive.

IQ is often used to measure impaired neurological development in low birthweight children because it is easy to quantify and can be used across cultures. ${ }^{1}$ Behavioural problems and learning disabilities may, however, be more sensitive measures. Major disabilities, such as cerebral palsy, can be diagnosed in the first two years of life, but follow up into preschool or school age is necessary to assess children's IQ effectively. ${ }^{2}$ At that age, low birthweight children without major handicaps have been found to have significantly lower mean IQ than controls. ${ }^{1}$ However, several authors have found that low birthweight is associated with indicators of low socioeconomic status, which in itself is a strong determinant of children's IQ. ${ }^{3-13}$ Therefore, the negative impact of low birthweight per se on children's cognitive development may be overestimated because of confounding parental factors. Furthermore, several investigators have proposed the existence of an interaction between biological risk and environmental effects, such that children of low birthweight are particularly vulnerable to non-optimal environmental factors. ${ }^{12} 1415$

Child cognitive development is a complex process incorporating hereditary and constitutional factors ('nature'), factors related to the quality of care taking ('nurture'), and complex interactions between them. ${ }^{3} 1314$ 16-18 Many studies have implied that the predictive importance of socioeconomic status for child cognitive development is an effect of the child rearing environment alone. ${ }^{111219}$ The effect is more likely to be a combination of both 'nature' and 'nurture'. 31620 Furthermore, medical and social risk factors for giving birth to low birthweight infants vary according to health, economic, and possibly cultural characteristics. ${ }^{5}$ This may imply that factors applicable to disadvantaged populations may be less relevant in affluent societies.

Two basic strategies are available to counter the problem of confounding in follow up studies of low birthweight infants: one uses matched controls. The drawback of this method is that it is impossible to know what socioeconomic or parental factors to match for prospectively in the population. The second approach is to control for confounding during analysis by stratification or multivariate techniques. These methods have the advantage that a wide range of potential parental confounding variables can be assessed, and those that prove significant can be controlled for in the analysis.

This study involves children from a geographically defined region in a relatively affluent society. The aim was to: (i) estimate the magnitude of IQ reduction in low compared with normal birthweight preschoolers while controlling for a wide range of parental factors; (ii) evaluate if the predictive parental factors for child preschool verbal and nonverbal IQ are mainly socioeconomic and demographic, or related to childrearing and maternal wellbeing; (iii) test the hypothesis that the negative impact of low socioeconomic status for preschool cognitive development is greater for low birthweight children.

\section{Method}

All surviving children weighing less than 2000 $\mathrm{g}$ born in the county of Hordaland, Norway, between 1 April 1986 and 8 August 1988 
Table 1 Survival and major handicaps among liveborn infants with birthweights under $2000 \mathrm{~g}$ born during study period ${ }^{\star}$

\begin{tabular}{|c|c|c|c|c|}
\hline Birthweight group & Total & $<1000 \mathrm{~g}$ & $1000-1499 \mathrm{~g}$ & $1500-1999 \mathrm{~g}$ \\
\hline $\begin{array}{l}\text { Total liveborn } \\
\text { Survivors to } 5 \text { years of age } \\
\text { Neonatal survivors }{ }^{1} \\
\text { Multiple malformation/chromosomal } \\
\text { abberation }{ }^{2} \\
\text { Cerebral palsy }{ }^{3} \\
\text { Blind } \\
\text { Deaf } \\
\text { Eligible, intact survivors } \\
\text { Lost to follow up because they moved } \\
\text { Lost to follow up because they refused } \\
\text { Of those eligible, assessed at age } 5\end{array}$ & $\begin{array}{l}217 \\
189(87) \\
197(91) \\
\\
8(4) \\
12(6) \\
0 \\
1 \\
174(80) \\
20(11)^{5} \\
10(6)^{5} \\
144(83)^{5}\end{array}$ & $\begin{array}{l}2 \\
1 \\
0 \\
1 \\
16(48) \\
1 \\
0 \\
15(94)^{5}\end{array}$ & $\begin{array}{l}1 \\
6 \\
0 \\
0 \\
46(77) \\
7 \\
2 \\
37(80)^{5}\end{array}$ & $\begin{array}{c}5 \\
5 \\
0 \\
0 \\
112(90) \\
12 \\
8 \\
92(82)^{5}\end{array}$ \\
\hline
\end{tabular}

${ }^{1}$ Survivors through the fourth postnatal week.

${ }^{2} \mathrm{Six}$ of these children died before 5 years of age.

${ }^{3}$ Nine had spastic diplegia, 1 had spastic hemiplegia and 2 had spastic quadriplegia.

${ }^{4}$ Infants without cerebral palsy (by 2 years of age), deafness, chromosomal aberration, or multiple malformation.

${ }^{5} \mathrm{Per}$ cent calculated from the number of intact survivors.

${ }^{\star}$ Data are presented as the number of cases (per cent of total liveborn).

formed the basis for the study (table 1 ). The population of the county is 416000 (about $10 \%$ of that of the whole of Norway) and the annual number of births was 5653 to 6083 . Surviving children without cerebral palsy, blindness, deafness, multiple malformations or chromosomal aberrations were examined at 5 years of age (table 1). The control children were recruited from two sources. Second and thirdborn 5 year old children weighing more than $3000 \mathrm{~g}$ and with a gestational age of more than 37 weeks not in need of transfer to the neonatal unit were used as controls both in this study and in a parallel investigation of growth and development in small for gestational age children born of para I and para II mothers. ${ }^{21}$ The mothers of these children constituted a $10 \%$ random sample of the women recruited during pregnancy by general practitioners and obstetricians from a defined geographical region including the city of Bergen in Hordaland. Children with chromosomal aberrations, major neurological handicaps, and those whose mothers did not speak a Scandinavian language were excluded. To make the control group reflect the composition of first, second, and thirdborn children in the

Table 2 Pregnancy, perinatal, and neonatal data for 144 intact low birthweight infants assessed at 5 years of age (children without cerebral palsy, blindness, deafness, multiple malformations or chromosomal abberations) *

\begin{tabular}{|c|c|c|c|c|}
\hline Birthweight group & $\begin{array}{l}\text { Total } \\
(n=144)\end{array}$ & $\begin{array}{l}<1000 \mathrm{~g} \\
(n=15)\end{array}$ & $\begin{array}{l}1000-1499 \mathrm{~g} \\
(n=37)\end{array}$ & $\begin{array}{l}1500-1999 \mathrm{~g} \\
(n=92)\end{array}$ \\
\hline $\begin{array}{l}\text { Pre-eclampsia } \\
\text { Twin or triplet pregnancy } \\
\text { Placental abruption } 1 \\
\text { Small for gestational age, }<10 \text { percentile } \\
\text { Apgar score at } 5 \text { minutes, }<7 \\
\text { Ventilator treatment } \\
\text { Respiratory distress syndrome } \\
\text { Bronchopulmonary dysplasia } \\
\text { Perinatal sepsis or meningitis } \\
\text { Late sepsis }^{34} \\
\text { Neonatal seizures }\end{array}$ & $\begin{array}{l}44(31) \\
23(16) \\
13(9) \\
67(47) \\
15(10) \\
42(29) \\
37(26) \\
15(10) \\
4(3) \\
5(3) \\
1(0 \cdot 7)\end{array}$ & $\begin{array}{r}5 \\
1 \\
0 \\
7 \\
4 \\
14 \\
10 \\
8 \\
1 \\
0 \\
0\end{array}$ & $\begin{array}{r}19 \\
4 \\
2 \\
16 \\
7 \\
14 \\
12 \\
5 \\
1 \\
5 \\
1\end{array}$ & $\begin{array}{r}20 \\
18 \\
11 \\
44 \\
4 \\
14 \\
15 \\
2 \\
2 \\
0 \\
0\end{array}$ \\
\hline \multicolumn{5}{|c|}{$\begin{array}{lcc}\text { Cerebral ultrasound performed in all with birthweight of }<1500 \mathrm{~g}(n=52) & 4 \\
\text { Grades I-II haemorrhage } & 0 & 7 \\
\text { Grades III-IV haemorrhage } & 2 & 0\end{array}$} \\
\hline
\end{tabular}

${ }^{1}$ Abruption was preceded by first trimester haemorrhage in one case and pre-eclampsia in two cases.

2Two of these infants needed oxygen supplementation after 40 weeks' postmenstrual age.

${ }^{3}$ Proved by positive blood or spinal fluid culture, or suspected because of symptoms and blood infection parameters.

infection parameters.

mptoms starting after the first postnatal week.

Both children with ventricular dilation also had haemorrhage.

^Data are presented as the number of cases (per cent of those assessed at 5 years of age). general population of Hordaland county in 1987 (41\% firstborn children) 60 additional firstborn 5 year old children were randomly recruited. This was done by selecting the first child born at Haukeland Hospital, Bergen, after every 40th consecutive birth of birthweight above $3000 \mathrm{~g}$ and length of gestation above 37 weeks. Eighty four per cent of all births in the county were at this hospital. If a chosen control refused to participate or was untraceable, the next eligible child was chosen (second alternative). All control children and 134 of the 144 low birthweight children assessed at 5 years were born in the same regional hospital, Haukeland Sykehus. The rest were born in smaller hospitals in the region and transported to the regional hospital shortly after birth.

The project protocol was approved by the regional ethics committee on medical research, and written consent was obtained from all parents.

Pregnancy, birth, and neonatal data were recorded prospectively in standardised clinical records and later input on to computer (table 2). In managing the neonates written routines for treatment and documentation were consistently adhered to. A cerebral ultrasound scan was performed in all infants with birthweights of less than $1500 \mathrm{~g}(\mathrm{n}=52)$ at 2 days, 1 week, 2 to 3 weeks and at discharge using a GE RT $30005 \mathrm{MHz}$ sector transducer. Information regarding parental education, parental smoking habits, family income, and family and marital status was obtained from a questionnaire given to parents at the time of the 5 year examination.

Psychometric intelligence was assessed using a Norwegian version of the WPPSI-R IQ test. $^{22}$ The full scale IQ (FIQ) combines the performance IQ (PIQ) and the verbal IQ (VIQ) scores. PIQ reflects non-verbal problem solving abilities which include visuo-spatial and psychomotor processing abilities. VIQ reflects verbal abstraction, vocabulary, verbal reasoning and auditory perception. All children completed the PIQ items and all but one child (a low birthweight child) completed the VIQ items. Pure tone audiometry was used to diagnose hearing deficits which could affect test results. Maternal non-verbal problem solving abilities were assessed using the Raven Progressive Matrices. ${ }^{23}$

Maternal childrearing attitudes were assessed using a 65 item version of the Child Rearing Practices Report (CRPR). ${ }^{24-26}$ In this questionnaire a statement about an aspect of childrearing is given and the mother is asked to rate the items on a Likert scale from 'Strongly disagree' $=1$ to 'Strongly agree' $=6$. Dekovic et al reported that parental self-reporting using the CRPR corresponded with actual parental behaviour with their child. ${ }^{27}$ As childrearing attitudes are highly culture dependent, it has been recommended that factor analyses are undertaken, rather than depending on previously published scale constructs. ${ }^{24}$ Therefore, we performed factor analysis including both study and control groups, to reduce the number of variables. We undertook 
Table 3 Child IQ and demographic data for low birthweight and control families

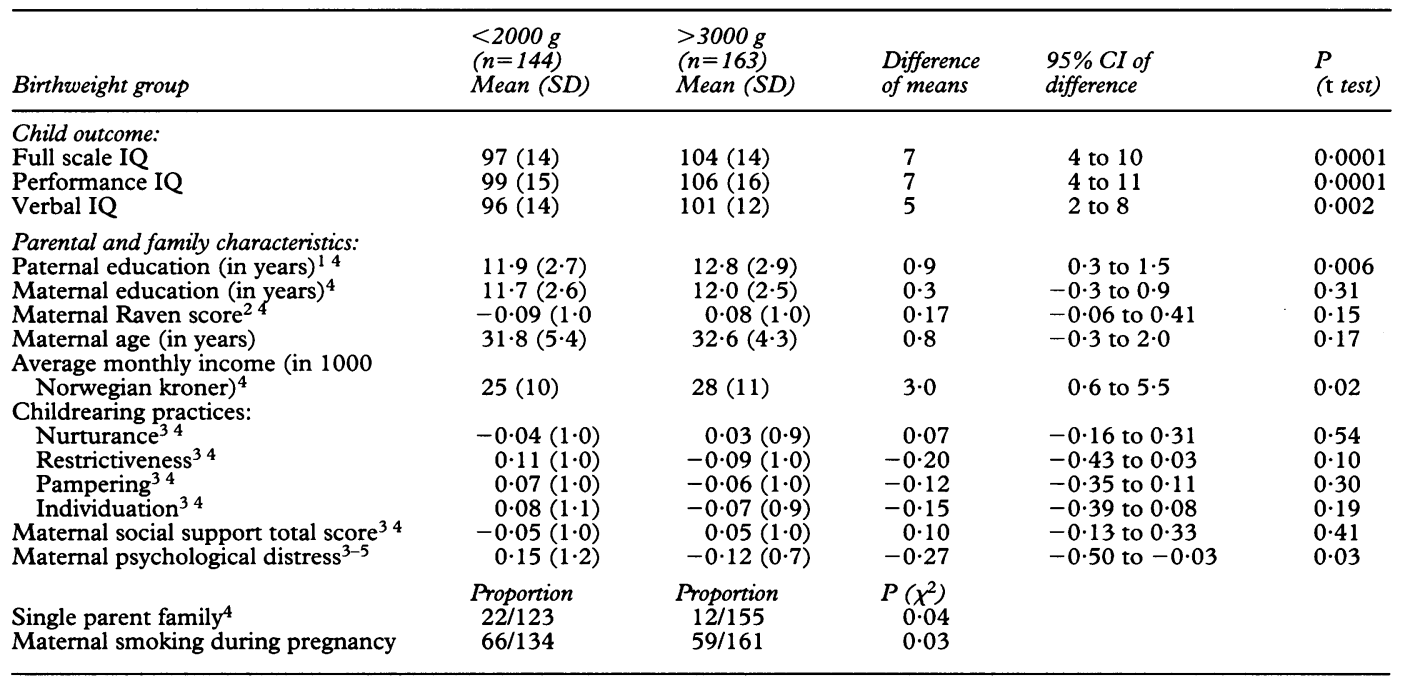

${ }_{1}^{1}$ Maternal education was used if the mother was the only caretaker $(n=32)$.

${ }^{2}$ Raven Progressive Matrices Test. The age corrected score, $\mathrm{z}$-transformed to a mean of 0 and a standard deviation of 1 is used.

${ }^{3}$ Factor scores z-transformed to a mean of 0 and a standard deviation of 1 were used.

${ }^{4}$ These variables were used in the multivariate analyses (table 4).

${ }^{5}$ SCL-90-R General Stress Index, more maternal distress in the low birthweight group.

principal components analysis, using Varimax rotation (SPSS Advanced Statistics, Release 5). Previous authors have identified two reliable factors, termed nurturance and restrictiveness. ${ }^{27} 28$ Inventory items with high loadings on the nurturance factor reflected a loving supportive maternal attitude, while those with high loadings on restrictiveness reflected such attitudes as respect, control of one's feelings and physical punishment.

Maternal satisfaction with social support network, including family, friends, and community support, was evaluated using the Inventory of Parents' Experiences (IPE). ${ }^{29}$ The authors of the inventory supplied a version which was modified to apply to 5 year old children. Total score was used in the analysis because it has been shown to possess better psychometric properties than subscale scores. ${ }^{30}$ We evaluated maternal psychological distress, such as depression, anxiety, and psychosomatic symptoms, using a Norwegian translation of the Symptom Check List Revised (SCL-90-R). ${ }^{31}$ The total score (Global Stress Index) was used rather than subscale scores, as this has proved more reliable. ${ }^{31}$

As previous research has indicated that PIQ has a stronger association with biological factors and VIQ with environmental factors in this age group, PIQ and VIQ were analysed separately rather than using FIQ in the main analyses. 2032

To facilitate interpretation of the analyses, the maternal Raven score, childrearing factor scores, maternal social support score and maternal psychological distress score were $z$ transformed to yield standardised variables with means of 0 and standard deviations (SD) of 1 .

\section{STATISTICAL ANALYSIS}

Firstly, mean group differences for the predictor and outcome variables were compared using $t$ tests, and differences in proportions using the $\chi^{2}$ test (table 3 ).

Secondly, the predictor variables presented in table 3 were subjected to hierarchical stepwise multiple linear regression analyses with child PIQ as the dependent variable. Cases with missing data on any of the variables included in the model were excluded from the analysis. In the stepwise procedure we used standard criteria for entry and removal of variables with probability levels of $P=0.05$ entry and $P=0.10$ for removal. To assess the crude correlation between child birthweight (entered as a $0-1=$ dummy variable, $0=$ low birthweight, $1=$ normal birthweight) and child PIQ, this variable was entered in Block 1 . Next, to assess the predictive significance of child birthweight while controlling for various socioeconomic and demographic variables, paternal education, maternal education, maternal Raven score, maternal smoking during pregnancy, and single parent family status were subjected to analysis in Block 2 using a stepwise procedure for selection of variables. Lastly, in Block 3, variables pertaining more specifically to the quality of the childrearing environment - namely, childrearing style, maternal social support, and maternal psychological distress - were entered in a similar manner. Identical procedures were repeated with child VIQ as the dependent variable.

Thirdly, we investigated interactional effects for the strongest parental and family predictors of child PIQ from the multiple regression analyses. A new variable, the product of a parental variable and the birthweight group status variable, was computed. This variable, the parental variable, and birthweight group status variables were forcibly entered into a multiple regression analysis with child PIQ as the dependent variable. The procedure was repeated for VIQ. Similar procedures were repeated using the other strong parental and family predictor variables. 
Table 4 Results of hierarchical stepwise multiple linear regression analyses in combined low ( $n=116)$ and normal birthweight $(n=146)$ groups that had complete datasets for the variables analysed

\begin{tabular}{|c|c|c|c|c|c|c|}
\hline Analysis block & $\begin{array}{l}\text { Adjusted } \\
R \text {-squared }\end{array}$ & Independent variables & $B$ & $\begin{array}{l}95 \% C I \\
\text { of } B\end{array}$ & $\beta$ & $P$ \\
\hline \multicolumn{7}{|c|}{$\begin{array}{l}\text { Dependent variable: child performance } I Q \text { : } \\
\text { Block } 1\end{array}$} \\
\hline Birthweight group & 0.03 & Birthweight group & $-6 \cdot 1$ & -10 to $-2 \cdot 3$ & $-0 \cdot 19$ & $0 \cdot 002$ \\
\hline $\begin{array}{l}\text { Block } 2 \\
\text { Addition of socioeconomic } \\
\text { variables and maternal IQ }\end{array}$ & $0 \cdot 14$ & $\begin{array}{l}\text { Maternal Raven score } \\
\text { Paternal education } \\
\text { Birthweight group }\end{array}$ & $\begin{array}{r}3 \cdot 6 \\
1 \cdot 2 \\
-4 \cdot 9\end{array}$ & $\begin{array}{c}1.6 \text { to } 5.6 \\
0.5 \text { to } 1.9 \\
-8.6 \text { to }-1.2\end{array}$ & $\begin{array}{r}0 \cdot 2 \\
0 \cdot 21 \\
-0 \cdot 15\end{array}$ & $\begin{array}{l}0.0004 \\
0.0007 \\
0.01\end{array}$ \\
\hline $\begin{array}{l}\text { Block } 3 \\
\text { Addition of child rearing, } \\
\text { maternal wellbeing }\end{array}$ & $0 \cdot 15$ & $\begin{array}{l}\text { Maternal Raven score } \\
\text { Paternal education } \\
\text { Birthweight group } \\
\text { Nurturance }\end{array}$ & $\begin{array}{r}3 \cdot 7 \\
1 \cdot 3 \\
-4 \cdot 8 \\
1.9\end{array}$ & $\begin{array}{l}1.7 \text { to } 5.6 \\
0.6 \text { to } 1.9 \\
-8.5 \text { to }-1.1 \\
0.1 \text { to } 3.7\end{array}$ & $\begin{array}{r}0 \cdot 22 \\
0 \cdot 22 \\
-0 \cdot 15 \\
0 \cdot 12\end{array}$ & $\begin{array}{l}0.0002 \\
0.0004 \\
0.01 \\
0.04\end{array}$ \\
\hline $\begin{array}{l}\text { Child verbal IQ: } \\
\text { Block } 1 \\
\text { Birthweight group }\end{array}$ & 0.01 & Birthweight group & $-3 \cdot 5$ & -6.8 to -0.2 & $-0 \cdot 14$ & 0.04 \\
\hline $\begin{array}{l}\text { Block } 2 \\
\text { Addition of socioeconomic } \\
\text { variables and maternal IQ }\end{array}$ & $0 \cdot 25$ & $\begin{array}{l}\text { Maternal education } \\
\text { Paternal education } \\
\text { Monthly family income } \\
\text { Birthweight group }\end{array}$ & $\begin{array}{l}1 \cdot 1 \\
1 \cdot 0 \\
0 \cdot 19 \\
-2 \cdot 4\end{array}$ & $\begin{array}{l}0.5 \text { to } 1.8 \\
0.4 \text { to } 1.7 \\
0.06 \text { to } 0.34 \\
-5.3 \text { to } 0.5\end{array}$ & $\begin{array}{r}0 \cdot 23 \\
0 \cdot 22 \\
0 \cdot 18 \\
-0.07\end{array}$ & $\begin{array}{l}0.001 \\
0.003 \\
0.006 \\
0.23\end{array}$ \\
\hline $\begin{array}{l}\text { Block } 3 \\
\text { Addition of child rearing, } \\
\text { maternal wellbeing }\end{array}$ & $0 \cdot 28$ & $\begin{array}{l}\text { Paternal education } \\
\text { Maternal education } \\
\text { Monthly family income } \\
\text { Individuation } \\
\text { Restrictiveness } \\
\text { Birthweight group }\end{array}$ & $\begin{array}{l}1 \cdot 0 \\
1 \cdot 0 \\
0 \cdot 18 \\
1 \cdot 8 \\
-1 \cdot 6 \\
-1 \cdot 7\end{array}$ & $\begin{array}{l}0.4 \text { to } 1.7 \\
0.4 \text { to } 1.7 \\
0.04 \text { to } 0.32 \\
0.3 \text { to } 3.2 \\
-3.0 \text { to }-0.2 \\
-4.6 \text { to } 1.2\end{array}$ & $\begin{array}{r}0 \cdot 22 \\
0 \cdot 21 \\
0 \cdot 16 \\
0 \cdot 14 \\
-0 \cdot 13 \\
-0 \cdot 07\end{array}$ & $\begin{array}{l}0 \cdot 002 \\
0 \cdot 003 \\
0 \cdot 01 \\
0 \cdot 02 \\
0.03 \\
0 \cdot 26\end{array}$ \\
\hline
\end{tabular}

Low birthweight $v$ control group, child sex, paternal education, maternal education, maternal Raven score, single parent family status, maternal smoking during pregnancy, the four childrearing practices factor variables (nurturance, restrictiveness, pampering and individuation), maternal psychological distress and maternal social support were subjected to the analysis as independent variables. The independent variables in the table were those that made significant independent contributions to explaining variables. The independent variables in the table were those that madiance
variance in child IQ. B is the unstandardised regression coefficient.

\section{Results}

One hundred and forty four of $174(83 \%)$ eligible low birthweight children (table 1) and 163 of the $170(96 \%)$ eligible control children were examined at 5 years of age. For four of the $60(7 \%)$ firstborn control children, second alternatives had to be used. Of the other control children, four moved out of the region and three refused to participate. Seventy four of these $144(51 \%)$ low birthweight children and 89 of the $163(55 \%)$ control children were boys.

Mean birthweight of the low birthweight children was $1555 \mathrm{~g}$ (SD $368 \mathrm{~g}$ ) and mean gestational age 32 weeks (SD 3 weeks). Pregnancy and perinatal data are presented in table 2. There were no significant differences between eligible infants who were assessed $(n=144)$ and those who were not assessed at 5 years of age $(n=30)$ regarding mean birthweight (1560 $\mathrm{g}$ and $1573 \mathrm{~g}$, respectively), mean gestational age $(32.2$ and 32.8 weeks, respectively), or any other pregnancy, birth and neonatal variable, except that there were significantly fewer twins $(P=0.04)$ and more children had been intubated in the delivery room $(P=0.003)$ among those who were assessed. The mean corrected age at assessment was 61.1 months (SD 1.5 months) for the low birthweight children and 60.6 months (SD 0.8 months) for the controls. One hundred and thirty five of the 144 low birthweight, and 162 of the 163 control children, completed audiometry; the rest refused. Fourteen children had hearing deficits of 40 decibels or more at 1000 and/or $2000 \mathrm{~Hz}$ in both ears. Seven of the children were low birthweight and seven controls. Recurrent otitis media was the dominant cause of the hearing loss. However, these children did not have lower mean verbal or performance IQ than the rest of the children and were therefore retained for analysis.

One hundred and thirty $(90 \%)$ of the low birthweight and $149(91 \%)$ of the control mothers completed the Raven test. In the remaining cases the father accompanied the child or the mother refused. One hundred and thirty two (92\%) mothers of low birthweight children and $156(96 \%)$ control mothers completed the IPE, while $130(90 \%)$ of the mothers of low birthweight children and 158 $(97 \%)$ of the control mothers completed the SCL-90-R. One hundred and thirty two (92\%) mothers of low birthweight children and 158 (94\%) control mothers completed the CRPR. The principal components analysis of this questionnaire indicated that Eigen values started levelling off after four factors, at an Eigen value of $1 \cdot 7$. As this number of factors yielded factors that could be interpreted meaningfully, a four-factor model was chosen. From the contents of the items with high factor loadings on the different factors, the four factors were labelled nurturance, restrictiveness, pampering, and individuation. The items with high factor loadings on nurturance reflected a loving and supportive maternal attitude. Those with high factor loadings on restrictiveness reflected respect, control of one's feelings, and physical punishment. Items with high factor loadings on pampering reflected a pampering, overprotective, inconsistent rearing style. Items with high loadings on individuation reflected attitudes such as well defined rules, letting the child know when the mother was angry, and acknowledging the need for parents to have time for themselves.

Compared with the normal birthweight children, the low birthweight children were more often raised in single parent families, 


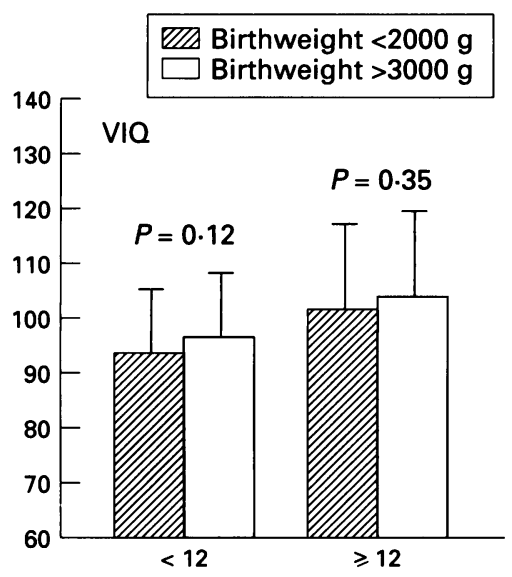

Paternal education (years)

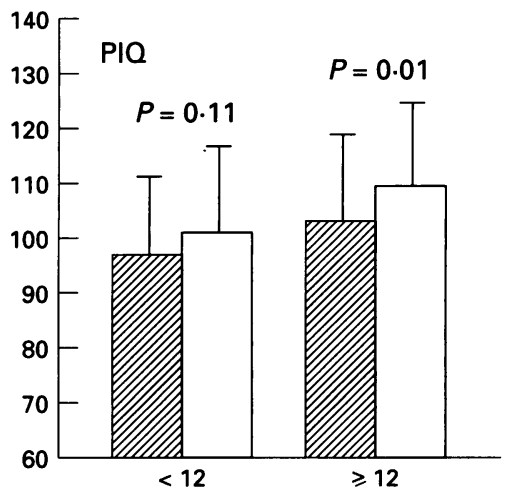

Paternal education (years)
Mean unadjusted performance IQ (PIQ) and verbal IQ (VIQ) for low birthweight compared with normal birthweight children, according to level of paternal education.

their fathers had less education, the mean monthly family income was lower, maternal smoking during pregnancy was more common, and maternal psychological distress was somewhat higher (table 3). The low birthweight families were comparable to the control families regarding length of maternal education, maternal Raven score, childrearing practices and maternal social support (table 3 ).

Mean unadjusted FIQ and PIQ were 7 points, and VIQ 5 points lower, for the low birthweight than for the control group (table 3). There were no significant differences in mean IQ between children with birthweights of less than $1500 \mathrm{~g}(\mathrm{n}=52)$ and those between 1500 and $2000 \mathrm{~g}(\mathrm{n}=92)$. Mean (SD) FIQ was 98 (16) $v 96$ (13), PIQ 99 (17) $v 99$ (14), and VIQ 97 (16) $v 96$ (13) in these two groups, respectively. For the 15 children with birthweights under $1000 \mathrm{~g}$ the corresponding figures were FIQ 97 (16), PIQ 97 (16), and VIQ 97 (15). There were no significant gender differences in IQ in either the low or normal birthweight groups. The 12 children who had cerebral haemorrhage on ultrasound scan in the neonatal period had a similar mean IQ to those who did not.

In the hierarchical stepwise multiple linear regression analysis the low birthweight children had a mean PIQ 6.1 points $(95 \% \mathrm{CI}, 2.3$ to $10, P=0.002$ ) below that of the normal birthweight children (Block 1 , table 4 ). The $6 \cdot 1$ points differ from the 7 points in the univariate analysis (table 3 ) because children with incomplete data were excluded. Birthweight category explained $3 \%$ of the variance (adjusted $R^{2}=0.03$ ) in child PIQ when none of the parental factors was controlled for. Socioeconomic and demographic variables (Block 2, table 4) explained an additional 11\%, and childrearing and maternal wellbeing variables an additional $1 \%$ of the variance (Block 3 , table 4). Controlling for all the parental variables the mean PIQ was 4.8 IQ points lower ( $95 \% \mathrm{CI}, 1 \cdot 1$ to $8 \cdot 5, \mathrm{P}=0.01$ ) for the low birthweight children. Altogether, the final model explained $15 \%$ of the variance in child PIQ. Removing the birthweight group status variable from the last block reduced the explained variance by $2 \%$, indicating that about $2 \%$ of the variance in child PIQ was attributable to birthweight and $13 \%$ to parental factors.

One standard deviation of the z-score for maternal Raven score corresponded to about 15 IQ points if maternal Raven score had been transformed to a standard IQ score. Using the unstandardised regression coefficient ( $B$ in table 4) for maternal Raven score, this means that an increase in maternal IQ of 15 points corresponded to an increase in child PIQ of 3.7 points. Similarly, for paternal education one year of additional education corresponded to a 1.3 point higher mean child PIQ score.

Similar reasoning applies to the multiple regression analyses with VIQ as the dependent variable (table 4). Mean verbal IQ was $3.5 \mathrm{IQ}$ points $(95 \% \mathrm{CI}, 0 \cdot 2$ to $6 \cdot 8, \mathrm{P}=0.04)$ lower for the low birthweight children than for controls, but this difference was rendered non-significant $(P=0 \cdot 26)$ when parental factors were controlled for. Socioeconomic and demographic variables (parental education and income) were the main predictors of child verbal IQ explaining $25 \%$ of the variance, but childrearing factors (individuation and restrictiveness) also contributed significantly and explained an additional $3 \%$.

Monthly family income was a significant predictor of child VIQ but not PIQ (table 4); but this item was left unanswered by 35 of 144 parents of low birthweight children and 21 of 163 control parents. The multivariate analyses for VIQ were therefore performed on a smaller sample. When the analyses were repeated without the income variable, the results were essentially the same, except that the model explained $5 \%$ less of the variance in child VIQ and the predictive strength of the paternal education variable was increased somewhat.

An identical regression analysis to those in table 4 was performed with child FIQ as the dependent variable. In this analysis $23 \%$ of the variance in child FIQ could be attributed to parental and family variables and an additional $2 \%$ to birthweight status. For those with birthweights of less than $1500 \mathrm{~g}$, the corresponding figures were $22 \%$ and $1 \%$.

No significant interaction effects were found for any of the investigated parental predictor variables for either PIQ or VIQ. However, there was a tendency towards a larger deficit in PIQ for the low birthweight children when paternal education was high, as mean PIQ was only significantly lower for the low birthweight children when paternal education was 12 years or longer (figure).

\section{Discussion}

The present study was population based, and demographic characteristics of the population, such as average income and proportion of urban $v$ rural residence, are similar to those of Norway as a whole. The distribution of birthweights and prevalence of malformations and chromosomal aberrations in the low birthweight group studied were also representative. ${ }^{33}$ The results are therefore representative 
for Norway and probably for other relatively homogeneous and affluent societies.

Parents of low birthweight children in our study were disadvantaged compared with the parents of normal birthweight children with regard to parental variables related to socioeconomic status. This is similar to reports from countries with a higher proportion of residents of low socioeconomic status. ${ }^{11}{ }^{34}$ However, the differences were small and limited to only some of the variables studied. The fathers had less education, the families had lower income, the parents were more often single, maternal smoking during pregnancy was more common and the mothers more often experienced psychological distress. The two groups were similar with regard to maternal education, social support, and Raven score, and childrearing practices. Controlling for the confounding effect of paternal education and family income, the crude mean performance IQ difference of $6 \cdot 1$ in favour of the controls was reduced to $4 \cdot 8$, and in the multivariate analysis only $2 \%$ of the explained variance in performance IQ was attributable to birthweight while $13 \%$ was attributable to parental factors. For verbal IQ the 3.5 point higher mean value for the control children was rendered non-significant after controlling for parental factors. These findings indicate that impaired preschool cognitive development attributable to low birthweight per se is small when confounding parental factors are adequately controlled for. Furthermore, in this relatively affluent society, parental education and problem solving abilities were much stronger predictors of child preschool IQ than childrearing and maternal wellbeing factors. Our findings also lend support to previous research indicating that performance IQ may be more determined by 'nature' (low birthweight, hereditary factors), while verbal IQ may be more determined by 'nurture' as family income and childrearing factors were stronger predictors of verbal IQ. $112035-37$

Other recent studies have reported a larger IQ deficit attributable to low birthweight or very low birthweight (very low birthweight, birthweight of less than $1500 \mathrm{~g}) .^{34} 38$ In a recent large population based British study the mean IQ at 8 years was 8.8 points lower for children with birthweights of less than $2000 \mathrm{~g}$ compared with controls matched for sex and class in school. ${ }^{34}$ However, important parental data were missing for $30-40 \%$ of the families. Our results included more complete data and more variables associated with parental factors, suggesting that the IQ difference related to low birthweight per se may have been overestimated in previous studies.

Hack et al reported that the mean 8 year performance and verbal IQ was 4 points lower in very low birthweight children than normal birthweight controls. ${ }^{10}$ Maternal education, race, and marital status were similar for the two groups, but a risk score computed from these three variables accounted for $31 \%$ of the variance in full scale IQ in the combined group of very low birthweight and control children, while only $2 \%$ of the variance could be attributed to birthweight status. ${ }^{10}$ Paternal education was not assessed. These findings are similar to those of the present study, where the corresponding figures for children with birthweights of less than $1500 \mathrm{~g}$ and controls were $22 \%$ and $1 \%$, respectively. In a study of 3 year old children from New Orleans, mean maternal IQ was 81 and child McCarthy IQ was 89 in the very low birthweight group compared to 102 and 107, respectively, in the control group. ${ }^{11}$ The difference in child IQ was substantially reduced, and the difference for receptive language was rendered non-significant after controlling for maternal IQ and socioeconomic status. Contrary to our findings, the mean maternal IQ was much lower for the very low birthweight group, illustrating that the significant parental confounding factors may not be the same for all societies.

A main finding of the present study is the dominant role of parental factors related to socioeconomic status over assessable childrearing and maternal wellbeing variables in predicting child preschool IQ. Sameroff and Seifer similarly concluded that socioeconomic factors (occupation, education, and race) were more important than variables assessing maternal mental illness, childrearing perspectives, and family stress in predicting child verbal IQ at 4 years of age. ${ }^{4}$ These findings can be interpreted in two different ways. First, child IQ, especially performance IQ, is strongly determined by hereditary factors. These factors are expressed in parental education and maternal non-verbal problem solving abilities, and to a lesser extent in paternal occupation. Very similar and strong relations between IQ in homozygotic twins reared apart and together support this interpretation. ${ }^{16}$ Second, factors in the childrearing environment which are important for cognitive development were not adequately expressed in the variables used to assess such factors in the present study. Because $85 \%$ of the variance in performance IQ and $72 \%$ of the variance in verbal IQ remained unexplained, the findings are compatible with such an explanation. Child cognitive development is more likely to be the result of complex processes involving both hereditary and environmental factors and the interactions between them. ${ }^{39}$

Hereditary mechanisms are probably important in affluent societies, while negative childrearing effects associated with social risk are more important in poor societies. Whatever the mechanism, the important point we have demonstrated is that parental factors, especially education and income, are strong predictors of child cognitive development, and that even small group differences for such factors may influence and confound group differences in child IQ. The common practice of simply matching or controlling for socioeconomic status on the basis of paternal occupation may therefore result in an overestimation of cognitive impairment caused by low birthweight or other similar risk factors. Many previous studies have included maternal rather than paternal education, presumably because 
mothers generally spend much more time with their preschool children than fathers do. Such an approach disregards the possibility of a hereditary component expressed in parental education variables. In the present study such a limitation would have overestimated the negative impact of low birthweight on child IQ as paternal and not maternal education was the important confounding variable. Our interpretation of this finding is that men, even in a society of relatively equal opportunity as Norway, are more likely to complete an education according to their intellectual potential than women who have children.

It has been claimed that the negative impact on cognitive development of a poor socioeconomic setting is greater for low birthweight than for normal birthweight children. ${ }^{12} \mathrm{~A}$ suggested explanation for this 'double hazard' is that the cognitive development of children with a biologically damaged brain is particularly vulnerable to non-optimal rearing. ${ }^{12}$ Such an effect has been demonstrated in normal birthweight infants showing abnormal neurological development at 8 months of age. ${ }^{14}$ However, the interactional effect was small compared with the much larger effect of socioeconomic status. One of the most cited studies in support of a 'double hazard' in children of low birthweight only demonstrated a strong negative effect of low socioeconomic status on child IQ.12 Additional risks attributable to low birthweight or other biological factors were not investigated as the study did not include controls of normal birthweight. In our study there were no significant interactions between birthweight and parental factors, indicating that the preschool cognitive development of low birthweight children is no more vulnerable to a non-optimal socioeconomic setting than that of normal birthweight children. In fact, the difference in performance IQ tended to be larger if the parents had good, rather than poor education.

Hack et al similarly reported that the negative effect of very low birthweight on IQ at 8 years of age was larger when social risk was low rather than high. ${ }^{10}$ Our study indicates that low socioeconomic status and low birthweight are independently and cumulatively associated with impaired cognitive development, and that the degree of impairment attributable to low birthweight is comparable, regardless of socioeconomic status and childrearing quality. ${ }^{10}$ Together with the study of Hack et al, it may even suggest that the qualities associated with a good socioeconomic setting may encourage optimal cognitive development for any child and disclose biological limitations, such as minor cerebral malfunction associated with being born prematurely.

Judged from the small difference in IQ attributable to low birthweight and the much larger impact of parental factors on cognitive development in children without major neurodevelopmental handicaps, it may be more important to establish programmes which identify the needs of deprived children in general, rather than to focus on low birthweight. However, an IQ score, even as late as 5 years, may lack the necessary sensitivity to identify children at risk of impaired neurological development, and a broader range of outcome measures, including child behaviour and personality, may need to be assessed before such conclusions can be drawn.

This study was financed by the Norwegian Research Council (NFR) Grant No: $102697 / 320$ and The Norwegian Red Cross Research Fund.

We thank Mrs Tone Flornes for invaluable help in collecting the data for this project and the rest of the staff at the Institute for Biological and Medical Psychology, University of Bergen, without whose help this project would have been impossible.

1 Ornstein M, Ohlsson A, Edmonds J, Asztalos E. Neonatal follow-up of very low birthweight/extremely low birthfollow-up of very low birthweight/extremely low birth-
weight infants to school age: a critical overview. Acta weight infants to school age: a critical

2 Anderson JE. The limitations of infant and preschool tests in the measurement of intelligence. $\mathcal{F}$ Psychol 1939; 8: 351-79.

3 Sameroff AJ. Environmental context of child development. $\mathcal{f}$ Pediatr 1986; 109: 192-200

4 Sameroff AJ, Seifer R. Familial risk and child competence. Child Dev 1983; 54: 1254-68.

5 Kramer MS. Determinants of low birth weight: Methodological assessment and meta-analysis. Bull WHO 1987; 65: 663-737.

6 Binsacca DB, Ellis J, Martin DG, Petitti DB. Factors associated with low birthweight in an inner city population: the role of financial problems. Am $\mathcal{f}$ Public Health tion: the role of

7 Ericson A, Eriksson M, Kallén B, Zetterström R. Socioeconomic variables and pregnancy outcome. Acta Paediatrica Scandinavica 1989; 360 (suppl): 48-55.

8 Scott DT. Premature infants in later childhood: some recent follow up results. Semin Perinatol 1987; 11: 191-9.

9 Naeye RL, Peters EC. Antenatal hypoxia and low IQ values. Am $\mathcal{F}$ Dis Child 1987; 141: 50-4.

10 Hack M, Breslau N, Aram D, Weissman B, Klein N, Borawski CE. The effect of very low birth weight and social risk on neurocognitive abilities at school age. 7 Dev Behav Pediatr 1992; 13: 412-20.

11 Pfeiffer SI, Aylward GP. Outcome for preschoolers of very low birthweight: sociocultural and environmental influences. Percept Mot Skills 1990; 70: 1367-78.

12 Escalona SK. Babies at double hazard: early development of infants at biologic and social risk. Pediatrics 1982; 70: infants

13 Wilson RS. Risk and resilience in early mental development. Dev Psychol 1985; 21: 795-805.

14 Willerman L, Broman SH, Fiedler M. Infant development, preschool IQ, and social class. Child Dev 1970; 41: 69-77.

15 Werner E, Simonian K, Bierman JM, French FE. Cumulative effect of perinatal complications and deprived environment on physical, intellectual, and social development of preschool children. Pediatrics 1967; 39: 490-505.

16 Bouchard TJ, McGue M. Familial studies of intelligence: review. Science 1981; 212: 1055-9.

17 Ramey CT, Bryant DM, Sparling JJ, Wasik BH. A biosocial systems perspective on environmental interventions for low birth weight infants. Clin Obstet Gynecol 1984; 27: 672-92.

18 Bee LH, Hammond MA, Eyres SJ, Barnard KE, Snyder C. The impact of parental life change on the early developThe impact of parental life change on the early deve
ment of children. Res Nurs Health 1986; 9: 65-74.

19 Weisglas-Kuperus N, Baerts W, Smrkovsky M, Sauer PJJ. Effects of biological and social factors on the cognitive development of very low birthweight children. Pediatric 1993; 92: 658-65.

20 Largo RH, Pfister D, Molinari L, Kundu S, Lipp A, Duc G. Significance of prenatal, perinatal and postnatal factors in the development of AGA preterm infants at five to seven years. Dev Med Child Neurol 1989; 31: 440-56.

21 Bakketeig LS, Jacobsen G, Hoffman JH, Lindmark G Bergsje P, Molne K, et al. Pre-pregnancy risk factors of small-for-gestational age births among parous women in Scandinavia. Acta Obstet Gynecol Scand 1993; 72: 273-9.

22 Wechsler D. Manual for the Wechsler preschool and primary scale of intelligence. New York: Psychological Corporation, scale of

23 Raven J. Progressive matrices. London: HK Lewis, 1965.

4 Block J. The child-rearing practices report (CRPR): a set of $Q$ items for the description of parental socialization, attitudes and items for the description of parental socialization, attitudes and
values. Berkeley: Berkeley University of California, values. Berkeley: Berkeley University
Institute of Human Development, 1965.

25 Goldberg WA. Marital quality, parental personality, and spousal agreement about perceptions and expectations fo children. Merrill Palmer Quarterly 1990; 36: 531-56.

26 Greenberger E, Goldberg WA. Work, parenting, and the socialization of children. Development Psychol 1989; 25 : $22-35$.

27 Dekovic M, Janssens JM, Gerris JR. Factor structure and construct validity of the Block Child Rearing Practices

28 Rickel AU, Biasatti LL. Modification of the Block Child Rearing Practices Report. F Clin Psychol 1982; 38: 129-34.

29 Greenberg MT, Crnic KA. Longitudinal predictors of developmental status and social interaction in premature 
and full term infants at age two Child Dev 1988; 59: 554-70

30 Sexton D, Thompson B, Scott RL, Wood TA. Measurement characteristics of the Inventory of Parent Experiences Scales. Topics in Early Childhood Special Education 1990; 10: 36-49.

31 Derogatis L. Administration, scoring and procedures manual I. Clinical Psychometric Research: Baltimore, 1983.

32 Vohr B, Garcia CC, Flanagan P, Oh W. Effects of intraventricular hemorrhage and socioeconomic status on perceptual, cognitive, and neurologic status of low birth weight infants at 5 years of age 7 Pediatr 1992; 121: 280-5.

33 Medical Birth Registry of Norway. Medica secular trends 1967-1984. Bergen: University of Bergen, secular 1987.

34 Pharoah POD, Stevenson CJ, Cooke RWI, Stevenson RC. Clinical and subclinical deficits at 8 years in a geographically defined cohort of low birthwei Child 1994; 70: 264-70.
35 Noble-Jamieson CM, Lukeman D, Silverman $M$, Davies PA. Low birth weight children at school age: neurological, psychological, and pulmonary function. Semin Perinatol 982; 6: 266-73

36 Roussounis SH, Hubley PA, Dear PR. Five year follow up of very low birthweight infants: neurological and psychological outcome. Child Care Health Dev 1993; 19: 45-59.

37 Sommerfelt K, Ellertsen B, Markestad T. Personality and behaviour in eight-year-old, non-handicapped children with birth weight under 1500 g. Acta Paediatr 1993; 82: 723-8.

38 Petersen MB, Greisen G, Kovacs R, Munck H, FriisHansen B. Status at four years of age in 280 children weighing $2300 \mathrm{~g}$ or less at birth. Dan Med Bull 1990; 37: w46-52.

39 McCall RB. Nature-nurture and the two realms of development: a proposed integration with respect to mental development. Child Devel 1981; 52: 1-12. 